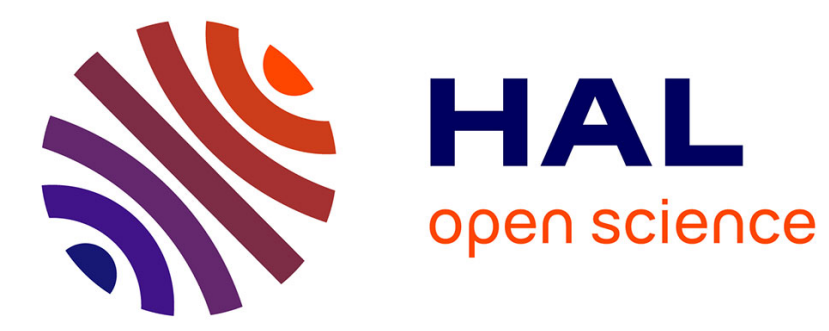

\title{
Changes in French weather pattern seasonal frequencies projected by a CMIP5 ensemble
}

\author{
Pierre Brigode, M. Gérardin, P. Bernardara, J. Gailhard, P. Ribstein
}

\section{To cite this version:}

Pierre Brigode, M. Gérardin, P. Bernardara, J. Gailhard, P. Ribstein. Changes in French weather pattern seasonal frequencies projected by a CMIP5 ensemble. International Journal of Climatology, 2018, 10.1002/joc.5549 . hal-01773657

\section{HAL Id: hal-01773657 \\ https://hal.science/hal-01773657}

Submitted on 23 Apr 2018

HAL is a multi-disciplinary open access archive for the deposit and dissemination of scientific research documents, whether they are published or not. The documents may come from teaching and research institutions in France or abroad, or from public or private research centers.
L'archive ouverte pluridisciplinaire HAL, est destinée au dépôt et à la diffusion de documents scientifiques de niveau recherche, publiés ou non, émanant des établissements d'enseignement et de recherche français ou étrangers, des laboratoires publics ou privés. 
1 Changes in French weather pattern seasonal frequencies projected by a CMIP5 ensemble

3

Brigode P. ${ }^{1,2, *}$, Gérardin, M. ${ }^{2}$, Bernardara P. ${ }^{1}$, Gailhard J. ${ }^{3}$ and Ribstein P. ${ }^{2}$

${ }^{1}$ LNHE, R\&D, Electricité de France (EDF), Chatou, France.

${ }^{2}$ UMR 7619 Metis, Sorbonne Université, Paris, France.

${ }^{3}$ DTG, DMM, Electricité de France (EDF), Grenoble, France.

* Now in: Université Côte d'Azur, CNRS, OCA, IRD, Géoazur.

Corresponding author: Pierre Brigode (pierre.brigode@unice.fr)

How to cite this article: Brigode P, Gérardin M, Bernardara P, Gailhard J, Ribstein P. Changes in French weather pattern seasonal frequencies projected by a CMIP5 ensemble. Int J Climatol. 2018; 1-16. https://doi.org/10.1002/joc.5549.

\section{Keywords:}

Weather pattern frequency; future weather pattern frequency; CMIP5; French climatology.

\section{Abstract (up to 300 words):}

Over the last decades, General Circulation Model (GCM) simulations have been regularly evaluated in terms of their ability to reproduce the historical frequency of significantly recurrent Weather Patterns (WP) observed at the regional scale. Thus, a good simulation of the frequency of these particular WP by the GCM is generally conditioning the good representation of the regional statistics of surface variables such as temperature and precipitation. In this paper, the seasonal frequency of eight particular WP have been calculated using the daily geopotential height fields simulated by an ensemble of 26 CMIP5 GCM. These WP are known as significantly influencing the French regional hydroclimatology in terms of both frequency of low flows and high precipitation events. Four different bias correction methods have been applied on the simulated geopotential height fields before the calculation of the seasonal WP frequencies. The GCM ensemble showed overall good performances in terms of the simulation of WP seasonal frequencies. The application of a spatially and temporally nonhomogenous correction of simulated geopotential height fields improved significantly the simulation of WP frequencies for the four seasons. Finally, the evolution of the WP frequencies over the next century has been quantified. Three WP (WP2, WP4 and WP8) have pronounced seasonal changes, with WP2 and WP4 being less frequent in summer and autumn seasons, respectively, while WP8 being more frequent over spring, summer and autumn seasons. The strong simulated frequency evolution of WP2 and WP8 is an interesting result, which predicts the climate to be drier with time for France. Thus, WP2 (western oceanic circulation), grouping rainy days over the northern France region, is simulated as less frequent in future summers, while WP8 (Anticyclonic situations), which groups nonrainy days over France, is simulated as more frequent in future summers. 


\section{INTRODUCTION}

Since several decades, meteorologists and climatologists have worked on the identification of particular atmospheric circulations patterns that are recurrently observed at the regional scale and that are strongly affecting the spatial and the temporal variability of surface variables, such as temperature and precipitation (e.g. over Europe by Plaut \& Simonnet, 2001 ; Cassou et al., 2005 ; Boé \& Terray 2008). Different classification methods are used for identifying a limited number of significantly recurrent circulation patterns (see Huth et al., 2008 for a review), generally based on the analysis of atmospheric circulation variables such as Sea Level Pressure (SLP) or geopotential heights (Vautard, 1990; Michelangeli et al., 1995). In the literature, the obtained recurrent circulations patterns have different names and are usually referenced as (weather, atmospheric, climate or circulation) regimes, types or patterns, based on their properties (Stephenson et al., 2004). Philipp et al. (2007) opposed the weather regimes (WR) to the weather patterns (WP) in terms of their spatial and temporal characteristics. The WR are usually one to four "quasi-stationary states of the large-scale circulation system" defined at the 10-day timescale, while the WP are more numerous situations defined at a finer spatial scale since being devoted to the classification of the circulation system on a daily timescale. The utility of WP classifications for quantifying the influence of large-scale climate drivers on hydro-climatological variability has been discussed by several studies, mainly arguing that WP are defined at an intermediate spatial scale between WR and local climatic observations (e.g. Giuntoli et al., 2013 ; Brigode et al., 2013a, 2013b).

Recently, WP frequencies have thus been used as a conditioning variable for the statistical modelling of extreme hydro-climatological values (e.g. Planchon et al. 2009; Brigode et al., 2013b). For example, several studies successfully linked WP (or circulation-related variables) to flood statistics at the regional scale (e.g. Nied et al., 2014; Wilby \& Quinn, 2013; Renard \& Lall, 2014). In the framework of the statistical modelling of extreme precipitation, Garavaglia et al. $(2010,2011)$ proposed an eight WP classification for sub-sampling precipitation events over France in terms of their synoptic origin. Tramblay et al. $(2011,2013)$ used the same WP classification as conditioning variables in a nonstationary extreme value frequency analysis and showed the soundness of using this framework for the statistical modelling of extreme precipitation in southern French regions. Furthermore, Giuntoli et al. (2013) found significant correlations between these WP and low flows over France, highlighting again the strong link between these WP and the seasonal French hydro-climatology.

These significant links are of particular interest in the context of the quantification of regional climate change impacts. Under the (strong) hypothesis that the statistical relationships observed over the historical period hold unchanged under climate changes, WP classifications can be used to downscale and transform changes of atmospheric circulations into changes of regional surface variables (Boé \& Terray, 2008). Nevertheless, this approach is based on the other hypothesis that atmospheric circulations are better simulated by the Global Circulation Models (GCM) than surface variables such as precipitation. At the global scale, numerous studies showed that large-scale features of the atmospheric circulation are among the variables that GCM represent with the best robustness (e.g. Covey et al., 2003; Räisänen, 2007), even though the ability of GCM to simulate changes in atmospheric circulation is recently questioned (e.g. Palmer, 1999; Corti et al., 1999; Hsu \& Zwiers, 2001; Gillett et al., 2003; Shepherd, 2014; Hall, 2014; Murawski et al., 2016). 
WR and WP classifications have been widely used as a way to evaluate GCM outputs in terms of their ability to reproduce WR and WP frequencies over a target region (Sheridan \& Lee, 2010). Frequencies of simulated WP have been evaluated over different regions, such as the Euro-Atlantic region (e.g. Demuzere et al., 2009; Handorf \& Dethloff, 2012 and Pastor \& Casado, 2012), the Arctic region (e.g. Cassano et al., 2006), the northwestern Iberian Peninsula (e.g. Lorenzo et al., 2011) and the Northwest America region (e.g. McKendry et al., 2006). Anagnostopoulou et al. (2008) used the $500 \mathrm{hPa}$ geopotential height $\left(Z_{500}\right)$ and the 1000-500 hPa thickness fields for WP classification over the eastern Mediterranean region and revealed several differences between observed WP frequencies and the frequencies simulated by the considered GCM (HadAM3P), with, for example, an overestimation of the summer frequency of anticyclonic situations. Sanchez-Gomez et al. (2009) evaluated the performances of an ensemble of 13 Regional Climate Models (RCM) forced by a reanalysis (ERA40) in terms of the simulation of WR over the Euro-Atlantic region and highlighted the good performances of the ensemble in terms of the simulation of the mean WR frequency. During the last years, the GCM outputs of the fifth Coupled Model Intercomparison Project (CMIP5, Taylor et al. (2012)) have been evaluated with the same methodology over different regions (e.g. by Belleflamme et al. (2013) over Greenland and by Dunn-Sigouin \& Son (2013); Hertig \& Jacobeit (2014) and Ullmann et al. (2014) over the Northern hemisphere), and the CMIP5 GCM appear to represent generally well the observed WR. Nevertheless, Belleflamme et al. (2014) and Santos et al. (2016) illustrated the limitations of two different GCM ensembles in simulating seasonal WP frequency over Europe for the recent decades. The ability of GCM to simulate WR and WP frequency seem thus to depend on the GCM considered, on the spatial scale considered and on the WR and WP classification method used.

The general aim of the paper is to quantify the frequency changes of the eight French WP previously defined by Garavaglia et al. (2010) simulated by an ensemble of 26 CMIP5 GCM over the $21^{\text {st }}$ century. Before studying future WP frequency changes, the performances of the GCM ensemble will be quantified over the historical period (here 1979-2004), using four different bias correction method applied on the GCM geopotential heights fields. 


\section{DATASETS}

\subsection{Reanalysis of geopotential height fields}

The ERA-Interim global atmospheric reanalysis (Dee et al., 2011, noted ERAi hereafter) has been used as reference for geopotential height fields for the historical period. This gridded dataset is available from 1979, at a $0.75^{\circ}$ spatial resolution and at a 12 -hour temporal resolution. Two levels have been considered in this study, namely (i) the geopotential height field at $1000 \mathrm{hPa}$ (noted $\mathrm{Z}_{1000}$ hereafter) and (ii) the geopotential height field at $700 \mathrm{hPa}$ (noted $\mathrm{Z}_{700}$ hereafter), both at 0 for each day. The historical period considered in this study is 1979-2004.

\subsection{GCM geopotential height field outputs}

Daily $Z_{1000}$ and $Z_{700}$ outputs from $26 \mathrm{GCM}$ have been considered in this study. All outputs have been generated within the fifth phase of the Coupled Model Intercomparison Project (CMIP5, Taylor et al., 2012). The GCM studied are listed in table S1. The daily outputs of three different experiments have been used:

- The "historical" experiment, which consists of a simulation of the recent past (1950-2005 period) under the historical forcing;

- The "RCP4.5" experiment, which extends the "historical" experiment by simulating the future (2006-2100) under the RCP4.5 emission scenario (radiative forcing surplus of $4.5 \mathrm{~W} \cdot \mathrm{m}^{-2}$ in 2100).

- The "RCP8.5" experiment, which extends the "historical" experiment by simulating the future (2006-2100) under the RCP8.5 emission scenario (radiative forcing surplus of $8.5 \mathrm{~W} . \mathrm{m}^{-2}$ in 2100).

The two emission scenarios considered here are members of the four Representative Concentration Pathway (RCP) scenarios considered in the CMIP5 experiments (Moss et al., 2010).

Only the first member (named r1ip1) from the historical, RCP4.5 and RCP8.5 experiments have been considered for each GCM. The simulated $Z_{1000}$ and $Z_{700}$ fields have been spatially interpolated on the ERAi grid $\left(0.75^{\circ}\right.$ grid spacing). The historical experiment outputs are considered over the 1979-2004 period (period of availability of the ERAi dataset) and the future experiment outputs are considered over the 2006-2098 period.

Several GCM outputs being produced by climate models with structural similarities (e.g. the bcc-csm11 outputs and the bcc-csm1-1-m outputs), a sub-sample of the 26 outputs has also been considered. Thus, the seasonal WP frequencies simulated using outputs produced by similar climate models (i.e. developed by the same institution) were averaged. The Table S1 presents the merging considered for the constitution of the second GCM ensemble (noted INS ensemble hereafter, where INS stands for "institution"), composed by 15 GCM outputs out of the 26 available.

\subsection{Precipitation reanalysis}

As an illustration of the regional precipitation patterns associated to each WP, the E-OBS daily precipitation reanalysis (Haylock et al., 2008, version 16.0) is used in this study. This reanalysis provides daily precipitation amounts at a $0.25^{\circ}$ resolution. This dataset has been used over Western Europe and the 1979-2004 period. 
143

144

145

146

147

148

149

150

151

152

153

154

155

156

157

158

159

160

161

162

163

164

165

166

167

168

169

170

171

172

173

174

175

176

177

178

\section{METHODOLOGY}

This section aims at describing the WP classification considered, the bias correction methods used and the frequency analysis methodology, all performed in the R-project environment (R Core Team, 2016, http://www.r-project.org/).

\subsection{The WP classification method}

\subsubsection{Average synoptic situation of the eight French WP}

The WP considered in the paper are the eight French WP defined by Garavaglia et al. (2010). These WPs have been defined at the daily time step through a classification of "rainy days" over southern France for the 1956-1996 period (see Garavaglia et al., 2010 and Brigode et al., 2013b for more details on the rainy days classification method). For example, the first WP (WP1) is constituted by 668 rainy days of the 1956-1996 period.

The synoptic characteristics of each of the eight WP have then been calculated by averaging the synoptic situations of the different days constituting each WP. Thus, the WP1 synoptic situation is the average of the synoptic situations of the 668 rainy days previously identified as constituting the WP1. Four geopotential height fields are considered for the synoptic description of each day and thus of each WP:

1. the $Z_{1000}$ field at $0 h$,

2. the $Z_{1000}$ field at $24 \mathrm{~h}$,

3. the $Z_{700}$ field at $0 h$,

4. the $Z_{700}$ field at $24 \mathrm{~h}$.

In this study, the average synoptic situation of each WP has been estimated with the ERAi geopotential reanalysis (available from 1979, see section 2) and thus computed over the 1979-1996 period. Geopotential height fields have been considered over 504 ERAi grid points, centered over southern France $\left(-7.50^{\circ}\right.$ to $12.75^{\circ}$ of longitude and $37.50^{\circ}$ to $50.25^{\circ}$ of latitude). Figure 1 shows the average $Z_{700}$ field at $24 \mathrm{~h}$ of each WP, estimated over the 1979-1996 period, and the spatial coverage of the 504 ERAi grid points.

\subsubsection{Classification of the historical period}

In order to obtain a daily classification for the studied historical period, each past day is assigned to one of the eight WP by computing distances between the synoptic situation of the studied day and each WP. Teweles \& Wobus (1954) distances (noted $D_{\text {TW }}$ hereafter) are calculated to find the closest WP to each considered day (see Brigode et al., 2013a, 2013b for more details). $D_{\text {TW }}$ focuses on air flows since this distance involves gradients of absolute values of geopotential heights (Woodcock, 1980; Obled et al., 2002; Bontron, 2004; Wetterhall et al., 2005, Brigode et al., 2016). The formula for estimating $\mathrm{D}_{\mathrm{TW}}$ between two synoptic situations (Z1) and (Z2) characterized by geopotential height fields on a gridded domain oriented south-north (index $i$ ) and west-east (index $j$ ) is :

$$
D_{\mathrm{TW}}=\frac{\sum_{\mathrm{i}, \mathrm{j}}\left|\mathrm{e}_{\mathrm{G}}^{\mathrm{i}}\right|+\sum_{\mathrm{i}, \mathrm{j}}\left|\mathrm{e}_{\mathrm{G}}^{\mathrm{j}}\right|}{\sum_{\mathrm{i}, \mathrm{j}}\left|\mathrm{G}_{\mathrm{L}}^{\mathrm{i}}\right|+\sum_{\mathrm{i}, \mathrm{j}}\left|\mathrm{G}_{\mathrm{L}}^{\mathrm{j}}\right|} \times 100
$$


where $\mathrm{e}_{\mathrm{G}}$ is the difference, around a given grid point, between the $\mathrm{Z} 1$ and $\mathrm{Z} 2$ geopotential gradients, while $G_{L}$ is the maximum of these two gradients in the direction considered ( $i$ or $j$ ):

$$
\begin{array}{r}
\left|e_{G}^{i}\right|=\left|\left(Z 1_{i, j}-Z 1_{i+1,1}\right)-\left(Z 2_{i, j}-Z 2_{i+1,1}\right)\right| \\
\left|e_{G}^{j}\right|=\left|\left(Z 1_{i, j}-Z 1_{i, j+1}\right)-\left(Z 2_{i, j}-Z 2_{i, j+1}\right)\right| \\
\left|G_{L}^{i}\right|=\max \left(\left|Z 1_{i, j}-Z 1_{i+1,1}\right|,\left|Z 2_{i, j}-Z 2_{i+1,1}\right|\right) \\
\left|G_{L}^{j}\right|=\max \left(\left|Z 1_{i, j}-Z 1_{i, j+1}\right|,\left|Z 2_{i, j}-Z 2_{i, j+1}\right|\right)
\end{array}
$$

$D_{\text {TW }}$ ranges from 0 for two identical geopotential fields and 200 for two opposite geopotential fields. The final score between one day and one WP is the sum of four $D_{\text {Tw }}$ distances: (i) the $D_{\text {Tw }}$ between the $Z_{700}$ fields at $0 h$, (ii) the $D_{\text {Tw }}$ between the $Z_{1000}$ fields at $24 h$, (iii) the $D_{\text {Tw }}$ between the $Z_{700}$ fields at $0 \mathrm{~h}$ and (iv) the $D_{T w}$ between the $Z_{700}$ fields at $24 \mathrm{~h}$. The $D_{\text {Tw }}$ calculation is illustrated in figure 1 , which shows the eight $D_{\text {Tw }}$ calculated between one particular day $\left(21^{\text {th }}\right.$ September 1992$)$ and the average synoptic situation of the eight French WPs for the $Z_{700}$ fields at $24 \mathrm{~h}$. The minimal $D_{T W}$ is found for the WP4 $\left(D_{T W}=48.4\right)$. The three other calculations of $D_{T W}$ for that particular day $\left(Z_{1000}\right.$ at $0 h, Z_{1000}$ at $24 \mathrm{~h}$ and $Z_{700}$ at $0 h$ ) are summarized in the table 1 . The sum of the four $D_{T w}$ is minimal for the WP4 ( $\left.D_{T W}=205.5\right)$ : the $21^{\text {th }}$ September 1992 is thus attributed to the WP4. Note that this synoptic situation has generated a considerable amount of precipitation in South-Eastern France, with more than $300 \mathrm{~mm}$ of precipitation observed locally that day (Benech et al., 1993), generating a catastrophic and deadly flash flood of the Ouvèze river (Sénési et al., 1996).

Table 1: $\mathrm{D}_{\text {Tw }}$ distances calculated between the $21^{\text {th }}$ September 1992 synoptic situation and the average synoptic situation of the eight French WPs for the $Z_{1000}$ and $Z_{700}$ fields at $0 \mathrm{~h}$ and at $24 \mathrm{~h}$. In this case, the $21^{\text {th }}$ September 1992 is finally attributed to the WP4.

\begin{tabular}{r|rrrrrrrr} 
& WP1 & WP2 & WP3 & WP4 & WP5 & WP6 & WP7 & WP8 \\
\hline$Z_{1000}$ at Oh & 91.9 & 101.1 & 85.3 & $\mathbf{6 7 . 9}$ & 95.2 & 81.1 & 70.7 & 96.8 \\
$\mathrm{Z}_{1000}$ at 24h & 92.0 & 91.7 & 67.6 & $\mathbf{5 2 . 2}$ & 89.6 & 84.1 & 64.2 & 99.6 \\
$\mathrm{Z}_{700}$ at Oh & 62.5 & 73.3 & 49.7 & $\mathbf{3 6 . 9}$ & 63.4 & 63.6 & 46.1 & 70.4 \\
$\mathrm{Z}_{700}$ at 24h & 74.7 & 82.1 & 59.0 & $\mathbf{4 8 . 4}$ & 79.8 & 71.4 & 56.8 & 86.6 \\
\hline D $_{\text {Tw }}$ sums & 321.1 & 348.2 & 261.6 & $\mathbf{2 0 5 . 5}$ & 328.1 & 300.3 & 237.7 & 353.4
\end{tabular}



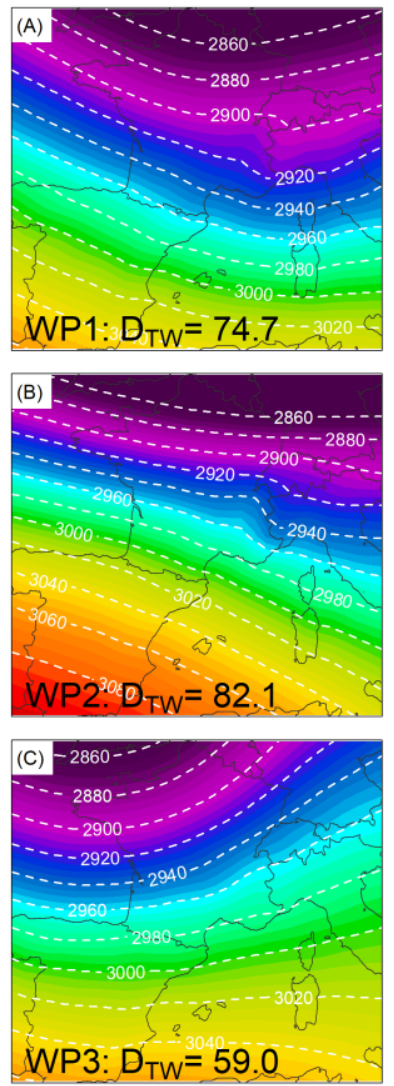
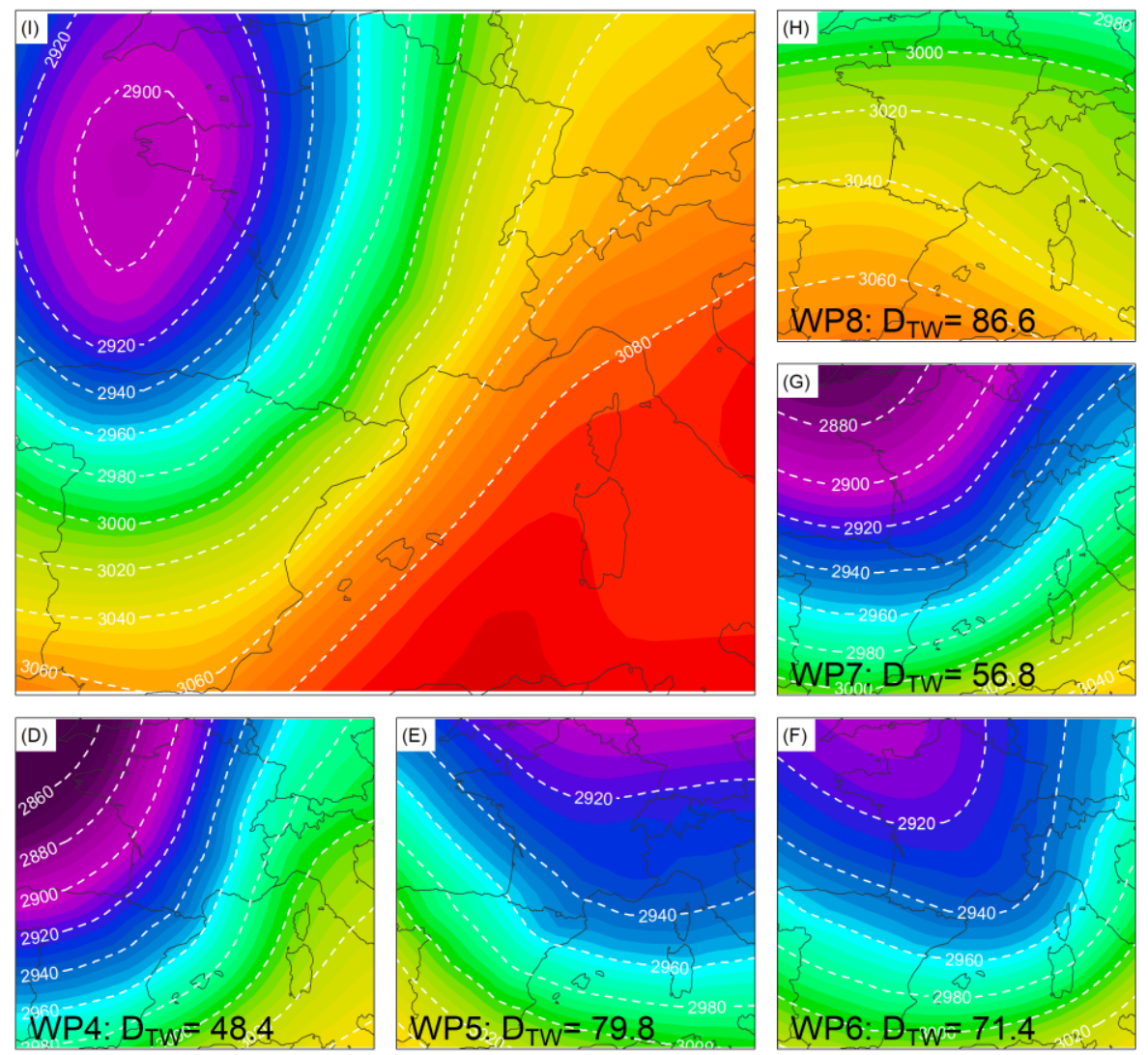

2900

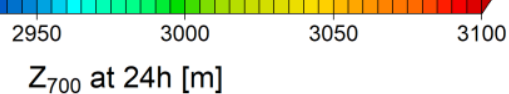

Figure 1: Comparison between the $Z_{700}$ synoptic situation of the $21^{\text {th }}$ September 1992 (at $24 h$, panel I) and the $Z_{700}$ situation of the eight French WP (panels $A$ to $H$ ). The $D_{T W}$ distances calculated between these geopotential fields are given on each panel.

\subsubsection{Meteorological description of the eight French WP}

The eight French WPs are described in the figures 2.1 and 2.2, in terms of average ERAi $Z_{700}$ and $\mathrm{Z}_{1000}$ fields at $\mathrm{Oh}, \mathrm{E}-\mathrm{OBS}$ regional precipitation pattern and seasonal frequencies, calculated over the 1979-2004 period. The eight WP can be grouped in terms of their general atmospheric flow direction (cf. column (a) of the figures 2.1 and 2.2, showing average SLP for each WP):

- WP1 (Atlantic Wave), WP2 (Steady Oceanic) and WP3 (Southwest Circulation) correspond to westerly oceanic circulation, grouping days particularly rainy over the Alps, the Northwestern part of France and the Western part of France, respectively. The WP2 is one of the most frequent over the year, especially during the winter season.

- WP4 (South Circulation), WP6 (East Return) and WP7 (Central Depression) correspond to Mediterranean circulations, grouping days particularly rainy over the Southeastern part of France. WP6 and WP7 days are relatively rarely observed.

- The WP5 (Northeast Circulation) corresponds to continental circulations, grouping days not particularly rainy over France. 
(a)
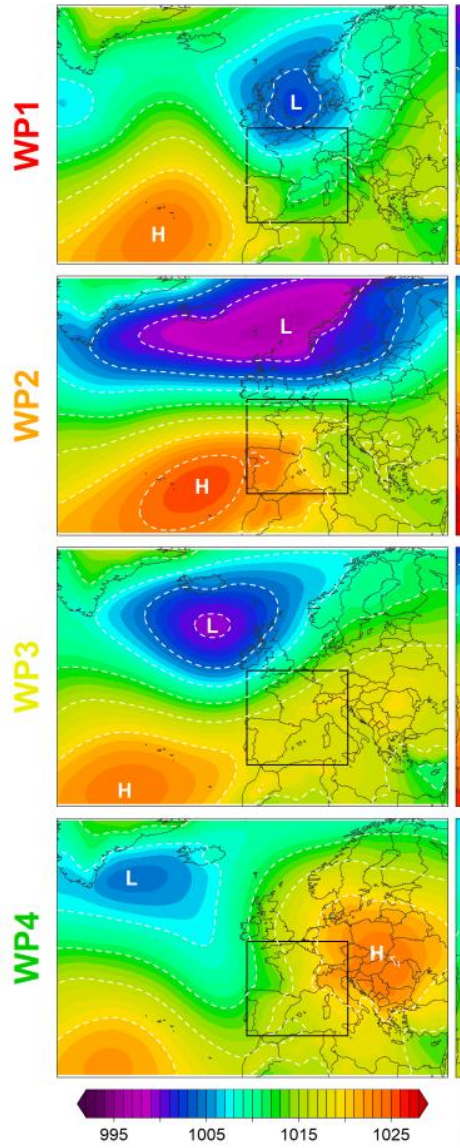

SLP at Oh [hPa] (b)
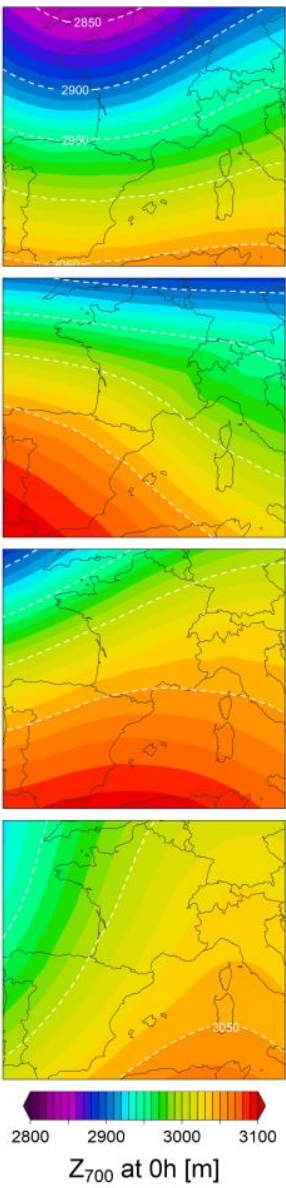

(c)
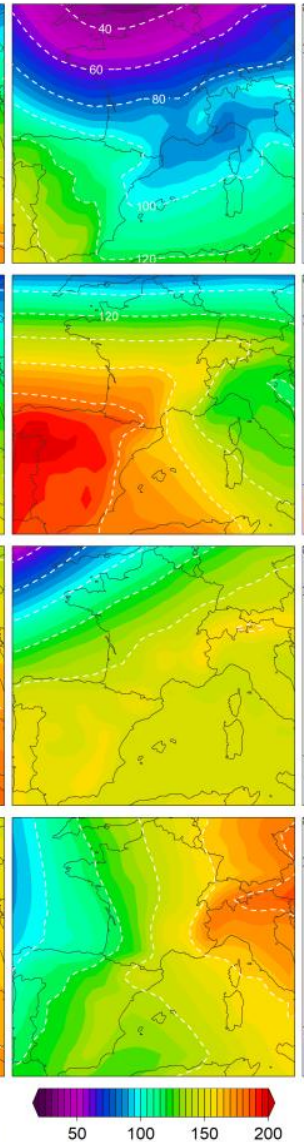

$\mathrm{Z}_{1000}$ at $\mathrm{Oh}[\mathrm{m}]$ (d)
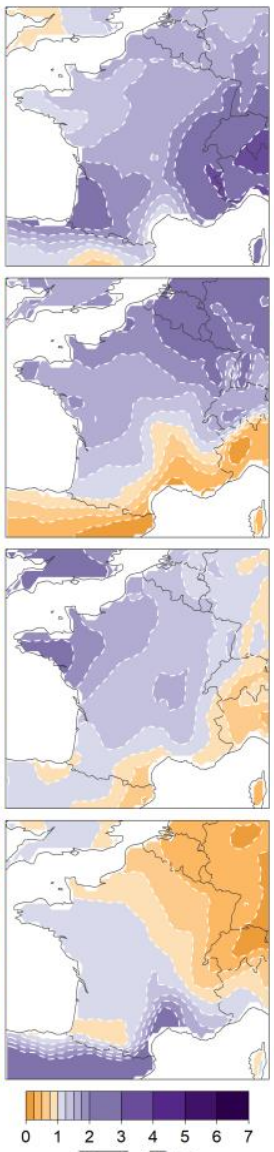

$\overline{\mathrm{P}_{\mathrm{WP}}} / \overline{\mathrm{P}}[-]$ (e)
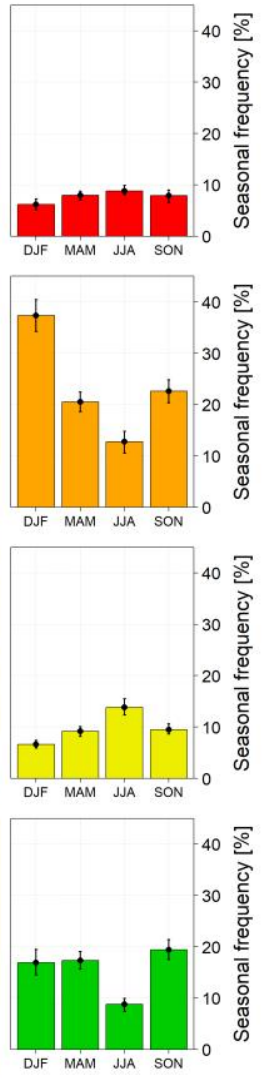

Figure 2.1: Description of the WP1 to WP4: (a) average ERAi SLP at Oh, (b) average ERAi $Z_{700}$ at Oh, (c) average $E R A i Z_{1000}$ at $O h$, (d) ratio between the E-OBS mean precipitation amounts and the general precipitation amount (considering all WP) and (e) seasonal frequency of the WP, estimated over the 1979-2004 period. 
(a)

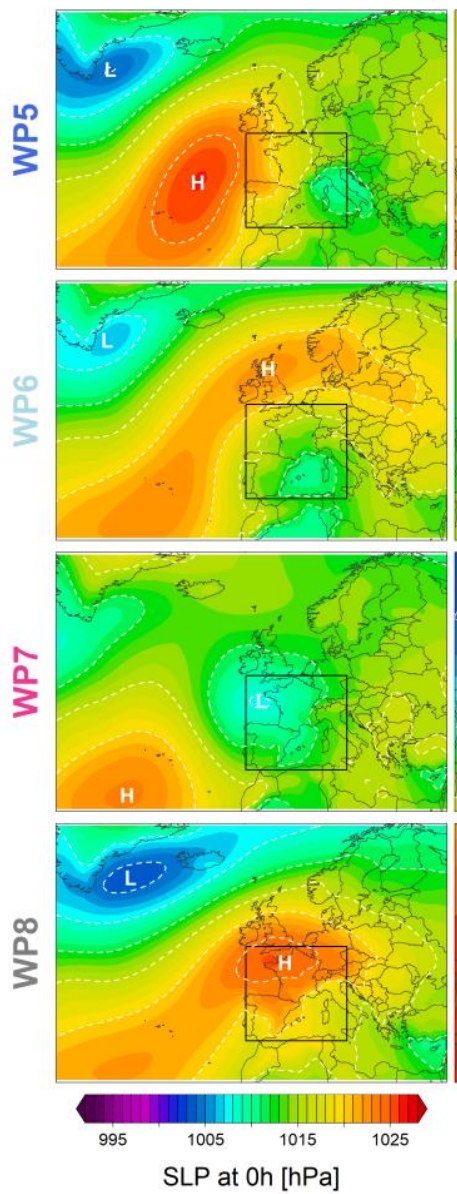

(b)
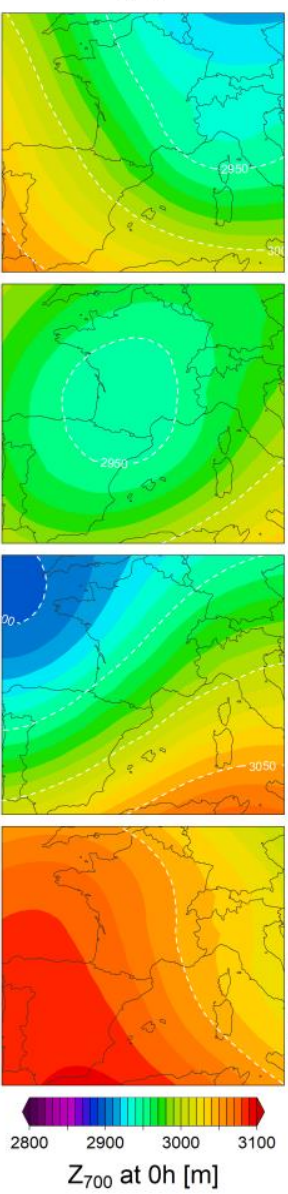

(c)
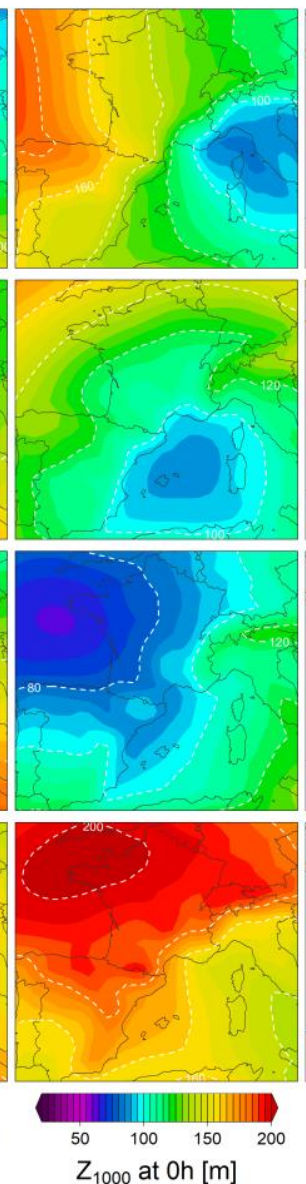

(d)
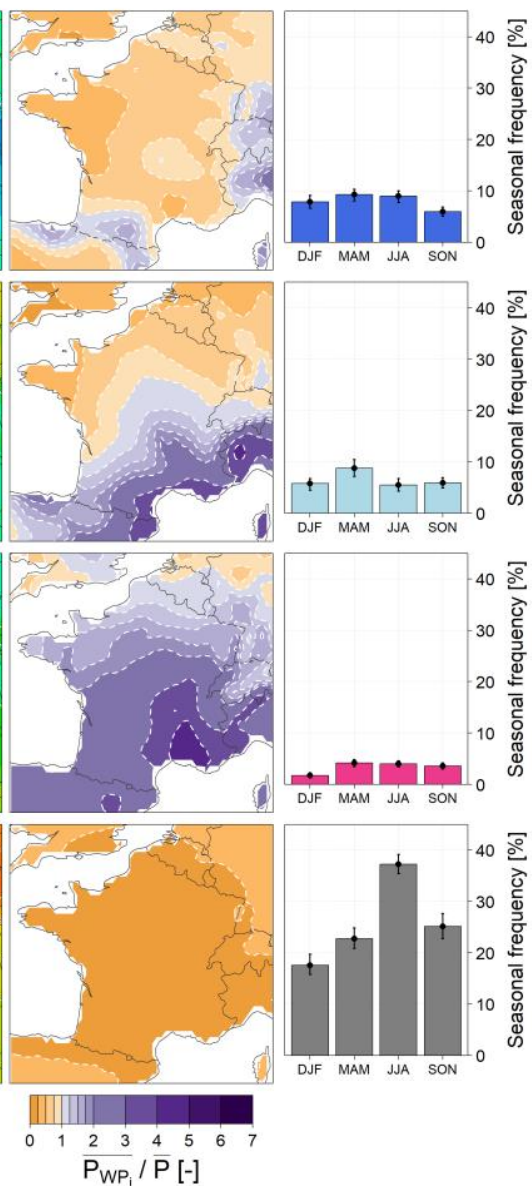

230

231

232

233

Figure 2.2: Description of the WP5 to WP8: (a) average ERAi SLP at Oh, (b) average ERAi $Z_{700}$ at Oh, (c) average $E R A i Z_{1000}$ at $O h,(d)$ ratio between the E-OBS mean precipitation amounts and the general precipitation amount (considering all WP) and (e) seasonal frequency of the WP, estimated over the 1979-2004 period.

\subsection{Classification of the daily GCM outputs}

The classification of the geopotential height fields simulated by the GCM has been done with the same methodology, i.e. by calculating $D_{\text {Tw }}$ between each simulated day (characterized by four synoptic situations: $Z_{1000}$ at $0 h, Z_{1000}$ at $24 h, Z_{700}$ at $0 h$ and $Z_{700}$ at $24 h$ ) and the ERAi average situations of the eight French WP (also being characterized by four synoptic situations). The sum of the four $D_{T w}$ is calculated for each simulated day and each WP, and the WP with the minimal $D_{\text {TW }}$ sum is attributed to the studied day.

\subsection{Geopotential height bias correction methods}

While most of the studies on the GCM WP simulation used uncorrected GCM outputs, it is noteworthy that Demuzere et al. (2009) and Lorenzo et al. (2011) found better performances of GCM in terms of frequencies if the SLP fields used for the classification were bias-corrected before the classification procedure. Thus, the need for bias correction of GCM geopotential height fields before performing WP classification will be tested in this paper, by considering different bias correction methods. 
$D_{\text {Tw }}$ distance values have been firstly computed without correcting the GCM geopotential height fields. The WP frequencies obtained by using these uncorrected GCM outputs are named DO hereafter. Then, four different bias correction methods have been applied to the GCM outputs:

1. A spatially homogeneous correction of the geopotential height average values and standard deviations. The outputs of this bias correction method are named D1 hereafter. Note that since $\mathrm{D}_{\mathrm{TW}}$ are estimated by considering synoptic circulation gradients, a spatially homogeneous correction of average values only is useless: lowering or rising the mean geopotential height fields has no effect on the $D_{\text {Tw }}$ values.

2. A spatially nonhomogeneous correction of the average values. The outputs of this bias correction method are named D2 hereafter.

3. A spatially nonhomogeneous correction of the geopotential height average values and standard deviations. The outputs of this bias correction method are named D3 hereafter.

4. A spatially nonhomogeneous correction of the monthly average values and standard deviations. The outputs of this bias correction method are named D4 hereafter.

To summarize, each GCM output is considered five times: firstly without any bias correction method (outputs named D0) and then after application of the D1, D2, D3 and D4 bias correction methods.

\subsection{Seasonal WP frequencies and frequency variability}

Seasonal frequencies of the eight French WP have been estimated over the 25 -year historical period (01/03/1979-29/02/2004) and over 68 25-year periods extracted from the future RCP simulations (2006-2031, 2007-2032, ..., 2073-2098). Four 3-month seasons have been defined: the autumn season (September, October and November, noted SON hereafter), the winter season (December, January and February, noted DJF hereafter) the spring season (March, April and May, noted MAM hereafter) and the summer season (June, July and August, noted JJA hereafter). For each season and each WP, frequencies are defined as the percentage of days belonging to the considered WP. The reference observed seasonal frequencies of the eight WP are the seasonal frequencies represented in column (e) of figures 2.1 and 2.2 .

In order to quantify the WP frequency variability within a time period, a non-parametric bootstrap resampling has been performed. Thus, for each 25-year time period considered, 100 samples of 15 randomly chosen years are constructed. Note that no replacements are allowed within this bootstrap resampling, and thus one particular year cannot be resampled twice. These 100 samples are then used to quantify the variability of the frequency by measuring the $90 \%$ confidence interval. The dispersion of observed WP frequencies are shown in figures 2.1 and 2.2 for the 1979-2004 period. The observed variability of the seasonal frequencies is limited, the highest variability is observed for the WP2, WP4 and WP8. For example, the summer frequency of WP8 ranges between $33.2 \%$ and $38.8 \%$. 


\section{RESULTS}

\subsection{GCM simulations of $W P$ average $Z_{1000}$ and $Z_{700}$}

The GCM ensemble outputs have been firstly evaluated in terms of the simulation of the average $Z_{700}$ and $Z_{1000}$ fields for the eight WP, over the 1979-2004 period. Figure 3 summarizes the spatial variability of the $Z_{1000}$ and $Z_{700}$ bias, calculated for each WP as the difference between the GCM ensemble mean fields and the average ERAi fields (presented in the figures 2.1 and 2.2). For $Z_{700}$, the GCM ensemble appears to overestimate the geopotential heights for the eight WP. The spatial distributions of theses biases reveal a slighter bias over northwestern France (Atlantic Sea). The spatial distribution of $Z_{1000}$ bias changes with WP. For WP1, WP5 and WP7, the GCM ensemble tends to underestimate the $Z_{1000}$ values over northwestern France and to overestimate the $Z_{1000}$ values over the southeastern part of the studied region. For the WP6, the $Z_{1000}$ values are slightly underestimated over the entire studied region. For the other WP (WP2, WP3, WP4 and WP6), the GCM ensemble tends generally to overestimate the $Z_{1000}$ values over the studied region. The spatial variability of biases justified the use of bias correction method that are spatially (D2 to D4) nonhomogeneous. 

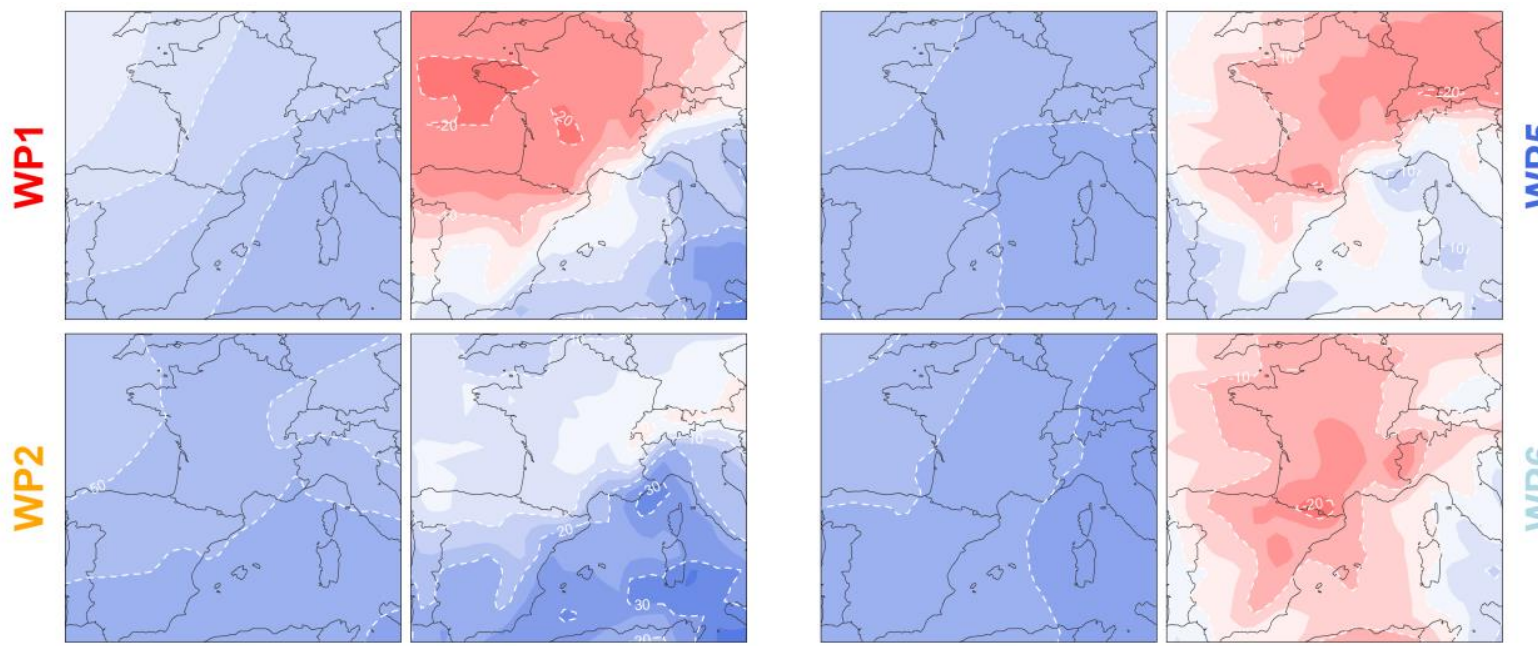

$\stackrel{n}{3}$
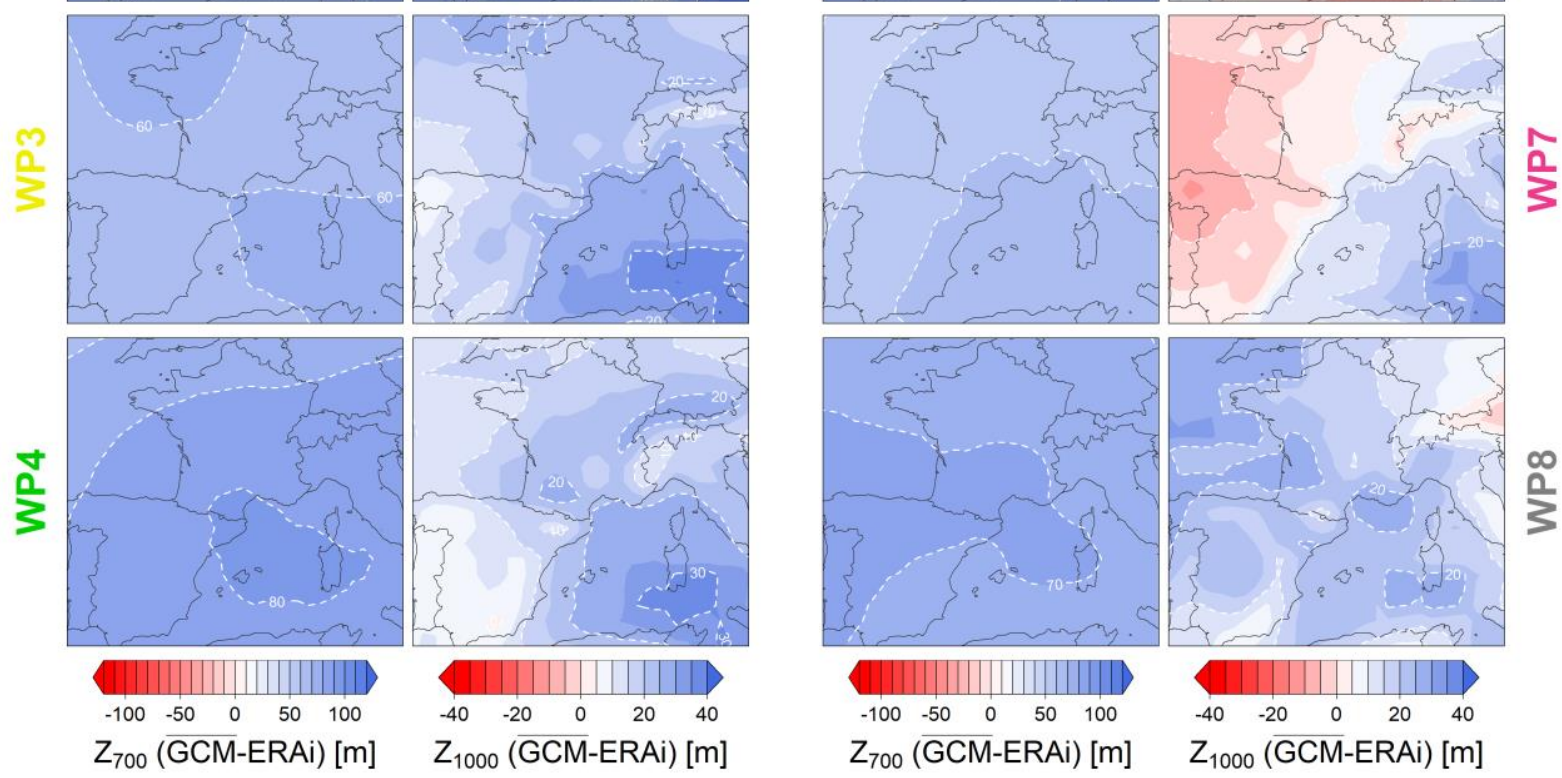

Figure 3: $Z_{700}$ and $Z_{1000}$ geopotential bias calculated for each WP as the difference between GCM ensemble mean and ERAi geopotential height fields.

\subsection{Historical seasonal WP frequencies simulated by the GCM ensemble}

The GCM ensemble has then been evaluated in terms of simulating historical WP frequencies for the four different seasons considered. Figure 4 presents the observed (ERAi) seasonal WP frequencies estimated over the 1979-2004 period and the WP frequencies simulated by the GCM ensemble (uncorrected and corrected). The seasonal variability of the WP frequencies are generally well simulated by the uncorrected GCM (expect for the WP4). Nevertheless, the frequencies of the two most frequent WP (WP2 and WP8) are poorly simulated, with WP2 frequencies being strongly overestimated and WP8 strongly underestimated. Moreover, the dispersion of the GCM ensemble is large for these two WP as well as for the WP4. The impact of the different bias correction methods on the historical WP frequencies is not straightforward and needs further investigations. 

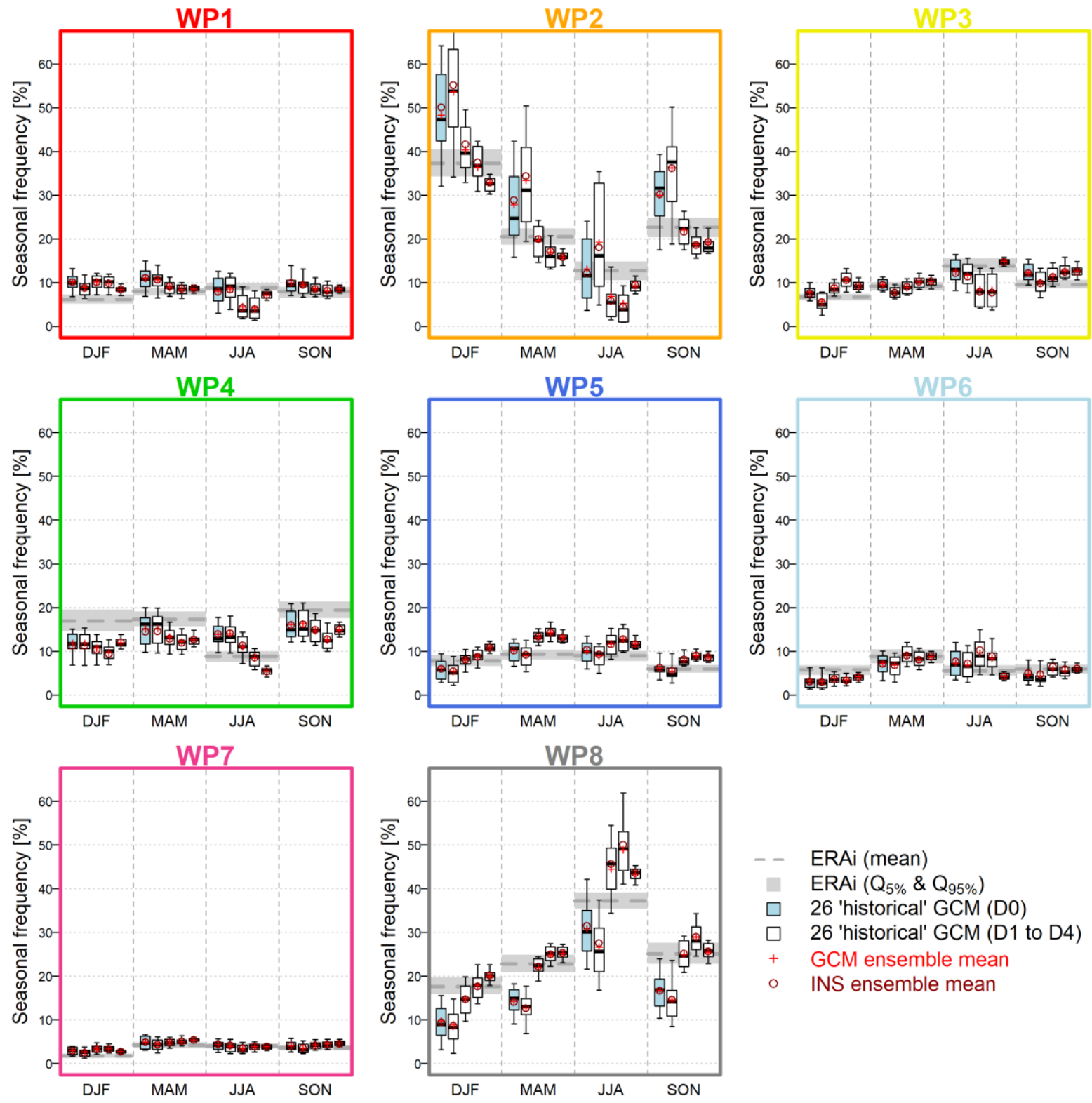

ERAi (mean)

$\operatorname{ERAi}\left(Q_{5 \%} \& Q_{95 \%}\right)$

26 'historical' GCM (D0)

26 'historical' GCM (D1 to D4)

GCM ensemble mean

INS ensemble mean

Figure 4: Seasonal WP frequencies estimated over the 1979-2004 period. The grey rectangles present the observed (ERAi) WP frequencies. The boxplots are constructed with the WP frequencies simulated by the GCM ensembles (GCM and INS) without bias correction (blue boxplots) and with bias corrections (white boxplots, D1 to D4).

Figure 5 presents the distribution of Euclidean distances calculated, for each season and each bias correction method, between the vector of the 8 observed WP frequencies and the 26 vectors of 8 simulated WP frequencies. When no bias correction is applied (DO method), the GCM ensemble is slightly less performant for DJF season (average distance around 19\%) than for other seasons (average distance around 15.5\%). The application of the D1 bias correction method (spatially homogeneous correction of the geopotential height standard deviations) appears to degrade the performance of the GCM ensemble in terms of seasonal WP frequencies. Nevertheless, the application of the D2 to D4 correction methods (all spatially inhomogeneous correction methods) improves the GCM ensemble performances for the DJF, MAM and SON seasons. For the JJA season, only the D4 bias correction 
method improves the performance of the WP frequency simulation. Overall, the D4 bias correction method (only method implying a spatial and temporal nonhomogenous correction) has the best performances in terms of simulation of the ERAi WP frequencies on the historical period.
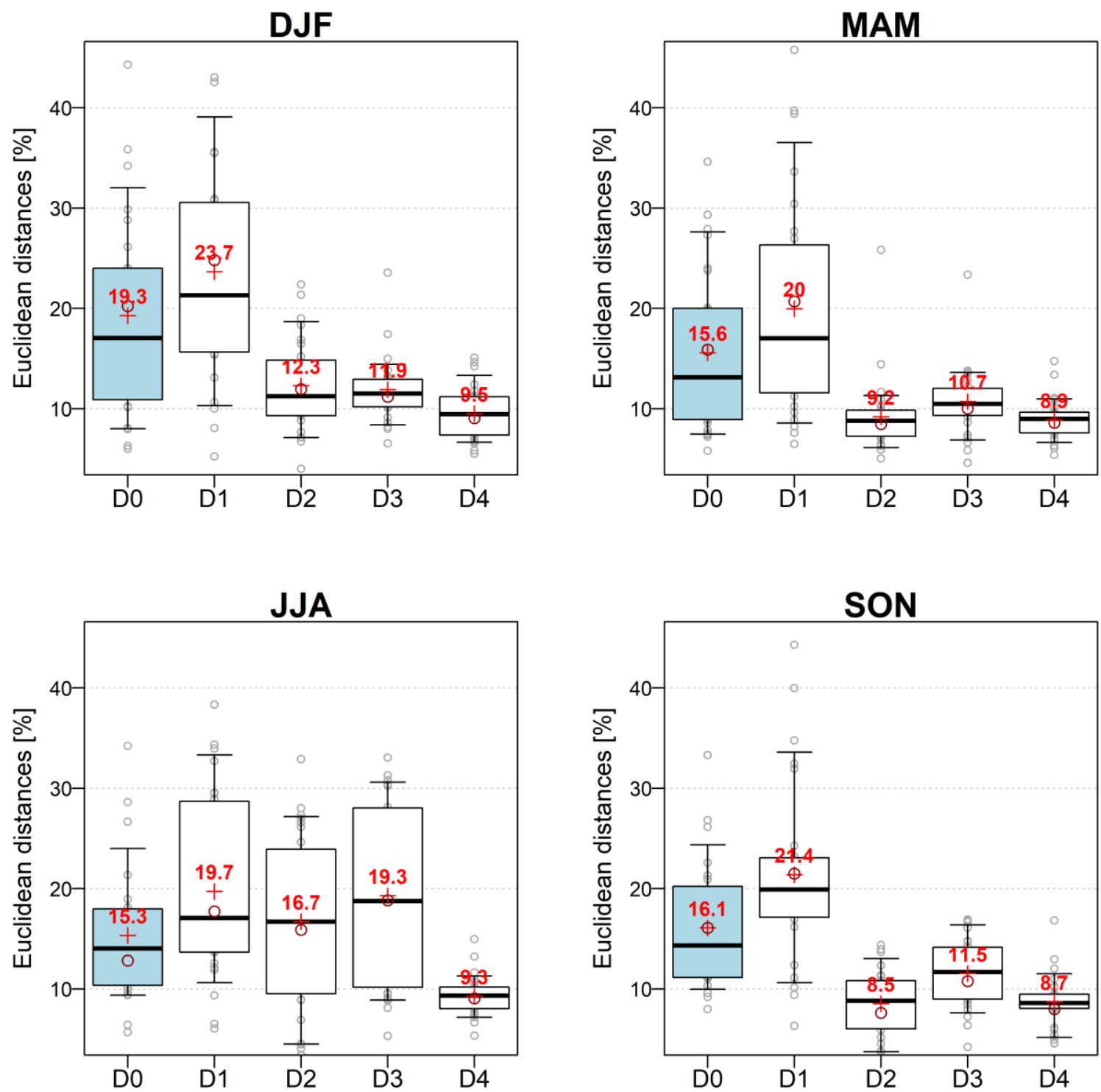

332

Figure 5: Distributions of seasonal Euclidean distances calculated, for each season and each bias correction method, between the vector of 8 observed WP frequencies and the 26 vectors of 8 simulated (GCM) WP frequencies over the 1979-2004 period. The blue boxplots are WP frequencies obtained without bias correction, and the white ones are obtained when the bias correction D1 to D4 are applied. Red values are mean values of Euclidean distances between WP frequency vectors and grey points are individual GCM distances. 


\subsection{Future evolutions of seasonal WP frequencies}

In this section, the changes of WP frequencies simulated by the GCM ensemble are calculated. Regarding the performances obtained by the four different bias correction methods tested (see Section 4.2), only the best method (D4) has been considered for the estimation of future WP frequencies. Thus, future frequencies are calculated with both uncorrected GCM outputs (D0) and GCM outputs corrected with the D4 method.

Figure 6 presents the mean seasonal frequency evolutions simulated by the GCM ensemble, considering both RCP4.5 and RCP8.5 emission scenarios and both GCM outputs without bias correction and GCM outputs corrected with the D4 method. None particular temporal evolutions throughout seasons are simulated for WP1, WP5, WP6 and WP7. WP3 and WP4 appear to be slightly less frequent at the end of the century during JJA and SON seasons, respectively. These slight decreases seem to be more pronounced when considering the RCP8.5 simulations. WP2 and WP8 are the two WP with the most pronounced seasonal changes and are in opposition. Overall, WP2 is slightly less frequent (but its frequency evolution depends on the RCP outputs considered), while WP8 is highly more frequent. These conjoint evolutions are particularly notable for the JJA season. For this season, WP8 frequency is constantly increasing with time for RCP8.5 outputs, while the frequency increase is stopped around the 2060 years for RCP4.5. Oppositely, the WP2 frequency decrease for the same season is stronger when considering RCP8.5 outputs. For the SON season, a strong increase of WP8 is also notable, while a slight decrease of WP4 and WP2 frequencies is found (expect for uncorrected RCP8.5 outputs). For the DJF and MAM seasons, the WP8 appears to be also more frequent, while no particular frequency evolution is found for WP2. 

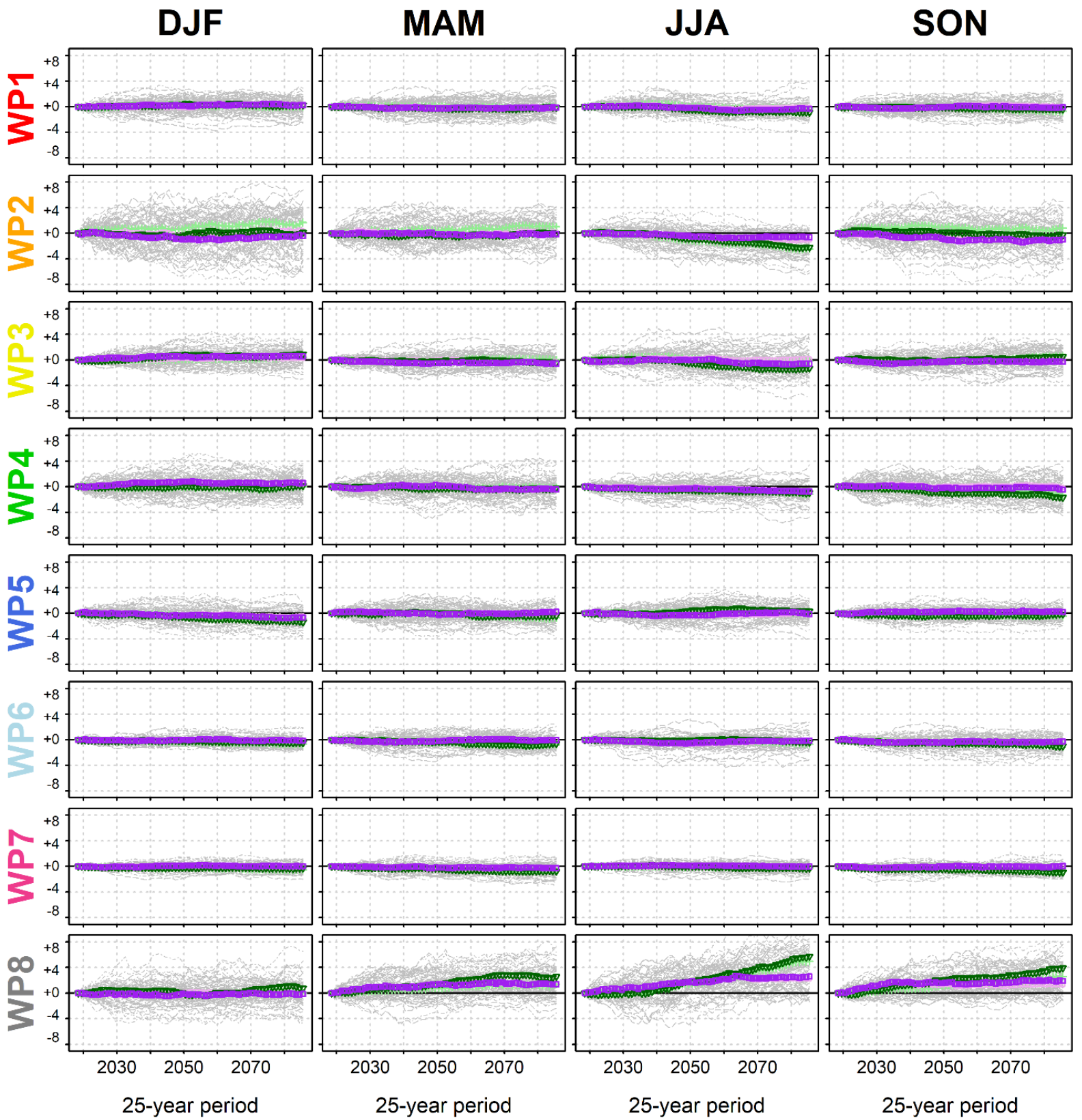

Figure 6: Seasonal WP frequency changes (in \%) estimated with the GCM ensemble over 68 consecutive $D 4$ bias correction method. Changes are relative to the WP frequencies simulated by the GCM ensemble over the first 25-year period (2006-2031). Grey lines are individual GCM WP frequency changes. 
Figure 7 summarizes the frequency changes calculated between the 2006-2031 period and the 2073-2098 period. A Student's t-Test has been performed for highlighting the significant changes of mean seasonal frequency ( $p$-value $<5 \%$ ). The dispersion of simulated changes is different depending on the WP, with larger dispersion for WP2, WP4 and WP8 frequencies. WP1 frequency appears to only slightly decrease in JJA months for the RCP8.5 simulations (-1.2\%, $95 \%$ of the GCM ensemble simulating a decrease), when geopotential height bias are corrected with the D4 method. For WP2, the simulated changes are highly dependent on the season and on the application of a bias correction method. After bias correction, no clear frequency changes are obtained when considering RCP4.5 outputs. Nevertheless, the RCP8.5 outputs show a significant decrease of WP2 frequency for the JJA season with the bias correction method applied (-2.7\%, $90 \%$ of the GCM ensemble simulating a decrease). WP3 appears to be slightly more frequent for DJF (significant increase of $+1.3 \%, 75 \%$ of the GCM ensemble simulating an increase, with D4 correction method), while being less frequent for JJA season (significant decrease of $-1.8 \%, 81 \%$ of the GCM ensemble simulating a decrease, with D4 correction method), for the RCP8.5 simulations. The summer decrease of the WP3 frequency is also found in the bias-corrected RCP4.5 simulations (significant decrease of $-0.7 \%, 58 \%$ of the GCM ensemble simulating a decrease). WP4 are significantly less frequent in JJA season RCP8.5 (-1.2\%, 81\% of the GCM ensemble simulating a decrease) scenarios and in SON season for bias corrected RCP8.5 (-2.2\%) scenarios. A significant decrease of $-1.8 \%$ in the DJF season is found for WP5 for the bias corrected RCP8.5 simulations (decrease simulated by $81 \%$ of the GCM ensemble), while no significant changes are found for the other seasons and outputs. The bias corrected RCP8.5 outputs show significant less WP6 days for the different seasons, with a stronger decrease for the SON season $(-1.5 \%, 95 \%$ of the GCM ensemble simulating a decrease).The WP7 is slightly less frequent for MAM, JJA and SON seasons, especially when considering RCP8.5 and bias-corrected outputs $(-1.1 \%,-0.4 \%$ and $-1.0 \%$ for these three seasons, decreases simulated by $81 \%, 67 \%$ and $81 \%$ of the GCM ensemble, respectively). Finally, the WP8 frequency is significantly increasing for MAM, JJA and SON seasons. These increases are stronger when considering bias corrected RCP8.5 outputs $(+3.3 \%,+7.4 \%$ and $+4.8 \%$, increases simulated by $81 \%, 95 \%$ and $90 \%$ of the GCM ensemble respectively).

The summer (JJA) $Z_{700}$ values simulated by the GCM ensemble is increasing with time over the studied domain. The GCM ensemble mean is $3137 \mathrm{~m}$ around 2018 and is $3183 \mathrm{~m}$ around 2085, considering the RCP8.5 scenario. This increase seems to be correlated with the decrease of the WP2 summer frequency and with the increase of the WP8 summer frequency (results not shown). Nevertheless, the WP classification was performed using the Teweles \& Wobus (1954) distance ( $\left.D_{T W}\right)$, metric calculated with the geopotential height gradients and not with the absolute values of the geopotential heights. Thus, the temporal increase of the geopotential height absolute values is not influencing the $D_{\text {TW }}$ calculation and the simulated increase (decrease) of the seasonal WP8 (WP2) frequency are thus due to changes in general circulation over the studied domain and not due to the global increase of surface pressure in future climate. 

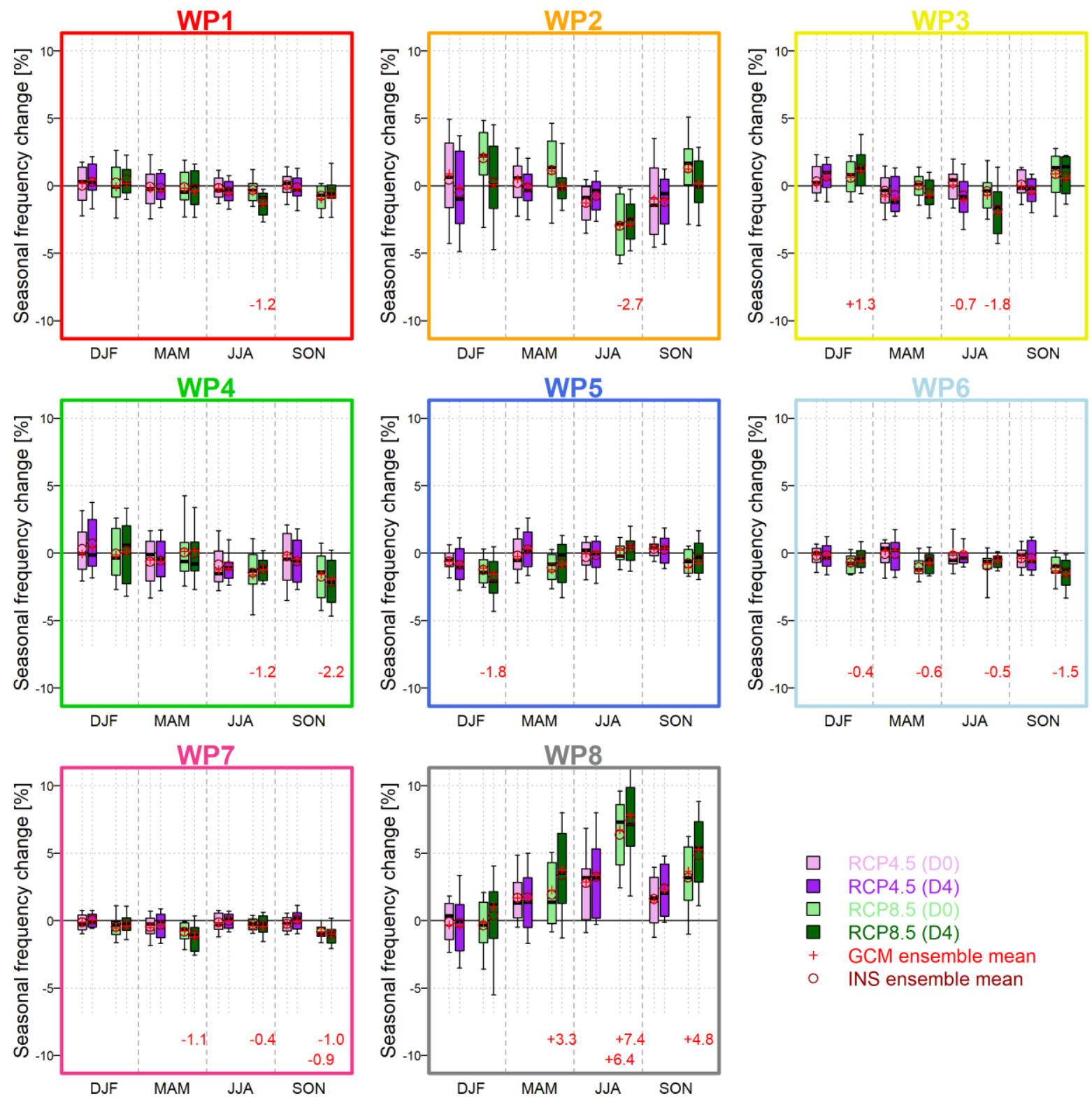

Figure 7: Seasonal WP frequency changes estimated with the GCM ensemble between 2073-2098 period and 2006-2031 period, considering RCP4.5 and RCP8.5 simulations, with no bias correction (DO) and with the D4 bias correction. The significant changes of mean WP frequency are printed in red color and expressed as percentage of frequency change. 


\section{DISCUSSION AND CONCLUSION}

An ensemble of 26 GCM used within the fifth Coupled Model Intercomparison Project (CMIP5) have been analyzed in order firstly to test its ability to reproduce observed seasonal geopotential height climatology over Western Europe, secondly to test its ability to reproduce the seasonal frequencies of eight French WPs previously defined (Garavaglia et al., 2010) and finally to estimate the future seasonal WP frequencies.

Firstly, biases of simulated $Z_{1000}$ and $Z_{700}$ have been quantified over Western Europe for the historical period (here 1979-2004), relatively to the ERAi reanalysis. For $Z_{1000}$, the GCM ensemble biases have both a strong spatial variability and seasonal variability. For example, the GCM ensemble tends to underestimate the geopotential heights at the highest latitudes of the Western Europe in DJF and MAM seasons, while it tends to overestimate geopotential heights at the same latitudes for the JJA and SON seasons. For $Z_{700}$, the GCM ensemble tends to overestimate the geopotential heights for the four seasons, with a slighter bias over northern latitudes. These spatial and seasonal variabilities of geopotential biases could advocate the use of spatially and seasonally inhomogeneous bias correction methods on the geopotential height outputs.

Secondly, the ability of the GCM ensemble to reproduce historical WP frequencies has been quantified and revealed that the seasonal variability of the WP frequencies are generally well simulated by the uncorrected GCM ensemble (expect for the WP4), with a slightly worse performance obtained for the DJF season. Nevertheless, the frequencies of the two most frequent WP (WP2 and WP8) are poorly simulated by the ensemble, with WP2 frequencies being strongly overestimated and WP8 strongly underestimated. Similar results have been obtained by Santos et al. (2016) by looking at WP frequencies simulated by an ensemble of 22 GCM over Western Europe and showing the overestimation by this other ensemble of the frequency of WP associated with zonal airflow. The use of four different bias correction methods showed that the application of a spatially and temporally nonhomogeneous correction of geopotential height fields (here the correction named D4) improved significantly the simulation of WP frequencies for the four seasons.

Finally, the evolution of the WP frequencies over the next century has been quantified, considering two emission scenarios (RCP4.5 and RCP8.5) and considering one bias correction method (D4) and no bias correction. The WP2, WP4 and WP8 have more pronounced seasonal changes, with WP2 and WP4 being less frequent in JJA and SON seasons, respectively, while WP8 being more frequent over MAM, JJA and SON season. The frequency changes calculated are higher for RCP8.5 simulations than for RCP4.5. Moreover, the temporal evolution of the WP frequencies appears to be constant over time for RCP8.5, while the evolution stops around the year 2060 for the RCP4.5 scenario. The use of a bias correction method is important in this context, since the significant mean changes of WP frequencies are all obtained with bias-corrected outputs (expect the increase of WP8 summer frequency). Nevertheless, the analysis of the temporal evolution of WP frequencies (figure 6) and the distribution of simulated frequency changes (figure 7) showed that the bias-correction method used (D4) is not changing the sign of the mean frequency changes compared to the uncorrected GCM outputs. Note that the use of three other bias correction methods (D1 to D3) leads to the same change signs for the different WP and seasons (results not shown). 
The strong simulated frequency evolution of WP2 and WP8 is an interesting result, which predicts the climate to be drier with time for France. Thus, WP2 (western oceanic circulation), grouping rainy days over the northern France region, is simulated as less frequent in future summers, while WP8 (Anticyclonic situations), which groups non-rainy days over France, is simulated as more frequent in future summers. These evolutions could have significant impacts on French low flows, since Giuntoli et al. (2013) recently highlighted strong correlations between these WP frequency and drought severity over France. An increase of the frequency of non-rainy WP is also found in the 22 GCM ensemble studied by Santos et al. (2016) when considering RCP8.5 outputs.

The bias of CMIP5 GCM in terms of the simulation of the eight French WP frequencies rises several questions, firstly about the WP classification methodology considered here. Thus, Vrac et al. (2007) showed that the WP classification method used has an impact on the identified patterns, and also that the choice of a given reanalysis as reference could lead to different WP classifications. Applying different classification methods on the same GCM ensemble and considering other reanalysis as reference would be an interesting perspective, in order to see if similar French WP are identified. In addition, the applied methodology assumes that only the WP frequencies are changing in the future, while WP structures are considered as constant in time. Küttel et al. (2010) thus highlighted large changes within type variations for European WP. The application of the methodology developed by Cattiaux et al. (2012) could be an interesting perspective in order to fully split the part of changes explained by WP frequencies and the part explained by WP structures, for example.

The second question to be raised is the spatial domain considered here for the definition of the WP classification and, consequently, for studying WP frequencies simulated by the GCM ensemble. This domain is rather small (-7.50 to $12.75^{\circ}$ of longitude and $37.50^{\circ}$ to $50.25^{\circ}$ of latitude), thus concerning only a limited grid points for the GCM characterized by a limited atmospheric horizontal resolution. If the WP identified at this spatial scale have relevant characteristics in terms of spatial distribution of surface variables such as precipitation over France, it is possible that the horizontal resolution of GCM are too large for allowing them to identify such regional patterns. Nuissier et al. (2011), with a rather similar objective of determining WP leading to heavy precipitation events over southern France, used a larger spatial domain for the WP classification $\left(-24^{\circ}\right.$ to $+39^{\circ}$ of longitude and $25.5^{\circ}$ to $63^{\circ}$ for latitude). Thus, trying to define French WP over a larger spatial domain is an interesting perspective, in order to quantify the future WP frequencies. The use of Regional Climate Model (RCM) could also be an interesting perspective, even though recent work questioned the ability of RCM to reproduce the daily weather regimes (e.g. Lucas-Picher et al., 2016).

Finally, the use of spatially nonhomogeneous bias correction methods for geopotential height fields is questionable, since these corrections change the simulated circulation patterns, transforming the GCM outputs in order to be more similar to the reference ones. Moreover, the biases quantified over the historical period have to be assumed as being stationary over time in order to be applied over the future time period considered, which is a strong hypothesis.

The ultimate goal of this work was to use simulated future frequencies of particular WPs - known to potentially leading to heavy precipitation events (and then extreme floods) - in order to discuss future precipitation (floods) frequency. Within this framework, only the frequency of future rainfall events is studied, thus splitting frequency (related to circulation dynamic) and intensity (related to thermo-dynamic parameters) of such events. Nevertheless, recent studies highlighted that both 
frequency and intensity have to be studied for discussing future extreme precipitation (e.g. Hertig et al., 2013; Blenkinsop et al., 2015) or climate extreme event attribution (e.g. Trenberth et al., 2015).

Finally, another interesting future work would be to study the potential shift of WP persistence over the same region and with the same GCM ensemble, since the persistence of rainy or non-rainy WPs is a good indicator for flood or drought frequency and intensity.

\section{ACKNOWLEDGEMENTS}

We acknowledge the World Climate Research Programme's Working Group on Coupled Modelling, which is responsible for CMIP, and we thank the climate modeling groups (listed in table S1 of this paper) for producing and making available their model output. For CMIP the U.S. Department of Energy's Program for Climate Model Diagnosis and Intercomparison provides coordinating support and led development of software infrastructure in partnership with the Global Organization for Earth System Science Portals. We also acknowledge the E-OBS dataset from the EU-FP6 project ENSEMBLES (http://ensembles-eu.metoffice.com) and the data providers in the ECA\&D project (http://www.ecad.eu). The authors thank the two reviewers, who provided constructive comments on an earlier version of the manuscript, which helped clarify the text.

\section{BIBLIOGRAPHY}

Anagnostopoulou C, Tolika K, Maheras P, Kutiel H, Flocas HA. 2008. Performance of the general circulation HadAM3P model in simulating circulation types over the Mediterranean region. International Journal of Climatology 28(2): 185-203. DOI: 10.1002/joc.1521.

Belleflamme A, Fettweis X, Erpicum M. 2014. Do global warming-induced circulation pattern changes affect temperature and precipitation over Europe during summer? International Journal of Climatology 35(7): 1484-1499. DOI: 10.1002/joc.4070.

Belleflamme A, Fettweis X, Lang C, Erpicum M. 2013. Current and future atmospheric circulation at 500 hPa over Greenland simulated by the CMIP3 and CMIP5 global models. Climate Dynamics 41(7-8): 2061-2080. DOI: 10.1007/s00382-012-1538-2.

Benech B, Brunet H, Jacq V, Payen M, Rivrain J-C, Santurette P. 1993. La catastrophe de Vaison-LaRomaine et les violentes précipitations de septembre 1992: aspects météorologiques. La Météorologie (1): 72-90.

Blenkinsop S, Chan SC, Kendon EJ, Roberts NM, Fowler HJ. 2015. Temperature influences on intense UK hourly precipitation and dependency on large-scale circulation. Environmental Research Letters 10(5): 054021. DOI: 10.1088/1748-9326/10/5/054021.

Boé J, Terray L. 2008. A Weather-Type Approach to Analyzing Winter Precipitation in France: Twentieth-Century Trends and the Role of Anthropogenic Forcing. Journal of Climate 21(13): 31183133. DOI: 10.1175/2007JCLI1796.1. 
Bontron G. 2004. Prévision quantitative des précipitations: adaptation probabiliste par recherche d'analogues. Utilisation des ré-analyses NCEP/NCAR et application aux précipitations du Sud-Est de la France. Institut Polytechnique de Grenoble, PhD thesis, 276 pp.

Brigode P, Brissette F, Nicault A, Perreault L, Kuentz A, Mathevet T, Gailhard J. 2016. Streamflow variability over the 1881-2011 period in northern Québec: comparison of hydrological reconstructions based on tree rings and geopotential height field reanalysis. Climate of the Past 12(9): 1785-1804. DOI: 10.5194/cp-12-1785-2016.

Brigode, P, Bernardara P, Gailhard J, Garavaglia F, Ribstein P, Merz R. 2013a. Optimization of the Geopotential Heights Information Used in a Rainfall-Based Weather Patterns Classification over Austria. International Journal of Climatology 33(6): 1563-1573. DOI:10.1002/joc.3535.

Brigode P, Mićović Z, Bernardara P, Paquet E, Garavaglia F, Gailhard J, Ribstein P. 2013b. Linking ENSO and heavy rainfall events over coastal British Columbia through a weather pattern classification. Hydrology and Earth System Sciences 17(4): 1455-1473. DOI: 10.5194/hess-17-1455-2013.

Cassano JJ, Uotila P, Lynch A. 2006. Changes in synoptic weather patterns in the polar regions in the twentieth and twenty-first centuries, part 1: Arctic. International Journal of Climatology 26(8): 10271049. DOI: 10.1002/joc.1306.

Cassou C, Terray L, Hurrell JW, Deser C. 2004. North Atlantic Winter Climate Regimes: Spatial Asymmetry, Stationarity with Time, and Oceanic Forcing. Journal of Climate 17(5): 1055-1068. DOI: 10.1175/1520-0442(2004)017<1055:NAWCRS>2.0.CO;2.

Cassou C, Terray L, Phillips AS. 2005. Tropical Atlantic Influence on European Heat Waves. Journal of Climate 18(15): 2805-2811. DOI: 10.1175/JCLI3506.1.

Cattiaux J, Douville H, Ribes A, Chauvin F, Plante C. 2012. Towards a better understanding of changes in wintertime cold extremes over Europe: a pilot study with CNRM and IPSL atmospheric models. Climate Dynamics 40: 2433. DOI: 10.1007/s00382-012-1436-7.

Corti S, Molteni F, Palmer TN. 1999. Signature of recent climate change in frequencies of natural atmospheric circulation regimes. Nature 398(6730): 799-802. DOI: 10.1038/19745.

Covey C, AchutaRao KM, Cubasch U, Jones P, Lambert SJ, Mann ME, Phillips TJ, Taylor KE. 2003. An overview of results from the Coupled Model Intercomparison Project. Global and Planetary Change 37(1-2): 103-133. DOI: 10.1016/S0921-8181(02)00193-5.

Dee DP, Uppala SM, Simmons AJ, Berrisford P, Poli P, Kobayashi S, Andrae U, Balmaseda MA, Balsamo G, Bauer P, Bechtold P, Beljaars ACM, van de Berg L, Bidlot J, Bormann N, Delsol C, Dragani R, Fuentes M, Geer AJ, Haimberger L, Healy SB, Hersbach H, Hólm EV, Isaksen L, Kållberg P, Köhler M, Matricardi M, McNally AP, Monge-Sanz BM, Morcrette J-J, Park B-K, Peubey C, de Rosnay P, Tavolato C, Thépaut J-N, Vitart F. 2011. The ERA-Interim reanalysis: configuration and performance of the data assimilation system. Quarterly Journal of the Royal Meteorological Society 137(656): 553-597. DOI: 10.1002/qj.828.

Demuzere M, Werner M, van Lipzig NPM, Roeckner E. 2009. An analysis of present and future ECHAM5 pressure fields using a classification of circulation patterns. International Journal of Climatology 29(12): 1796-1810. DOI: 10.1002/joc.1821.

Dunn-Sigouin E, Son S-W. 2013. Northern Hemisphere blocking frequency and duration in the CMIP5 models. Journal of Geophysical Research 118(3): 1179-1188. DOI: 10.1002/jgrd.50143. 
571 Garavaglia F, Gailhard J, Paquet E, Lang M, Garçon R, Bernardara P. 2010. Introducing a rainfall 572 compound distribution model based on weather patterns sub-sampling. Hydrology and Earth System 573 Sciences 14(6): 951-964. DOI: 10.5194/hess-14-951-2010.

574 Garavaglia F, Lang M, Paquet E, Gailhard J, Garçon R, Renard B. 2011. Reliability and robustness of rainfall compound distribution model based on weather pattern sub-sampling. Hydrology and Earth System Sciences 15(2): 519-532. DOI: 10.5194/hess-15-519-2011.

577 Gillett NP, Zwiers FW, Weaver AJ, Stott PA. 2003. Detection of human influence on sea-level pressure. 578 Nature 422(6929): 292-294.

579 Giuntoli I, Renard B, Vidal J-P, Bard A. 2013. Low flows in France and their relationship to large-scale climate indices. Journal of Hydrology 482: 105-118. DOI: 10.1016/j.jhydrol.2012.12.038.

Hall A. 2014. Projecting regional change. Science 346(6216): 1461-1462. DOI: 10.1126/science.aaa0629.

Handorf D, Dethloff K. 2012. How well do state-of-the-art atmosphere-ocean general circulation models reproduce atmospheric teleconnection patterns? Tellus $A$ 64(0). DOI: 10.3402/tellusa.v64i0.19777.

Haylock MR, Hofstra N, Tank AMG., Klok EJ, Jones PD, New M. 2008. A European daily high-resolution gridded data set of surface temperature and precipitation for 1950-2006. Journal of Geophysical Research 113(D20): D20119. DOI: 10.1029/2008JD010201.

Hertig E, Jacobeit J. 2014. Variability of weather regimes in the North Atlantic-European area: past and future. Atmospheric Science Letters 15(4): 314-320. DOI: 10.1002/asI2.505.

Hertig E, Seubert S, Paxian A, Vogt G, Paeth H, Jacobeit J. 2013. Statistical modelling of extreme precipitation indices for the Mediterranean area under future climate change. International Journal of Climatology 34(4): 1132-1156. DOI: 10.1002/joc.3751.

Hsu CJ, Zwiers F. 2001. Climate change in recurrent regimes and modes of northern hemisphere atmospheric variability. Journal of Geophysical Research 106(D17): 20145-20159. DOI: 10.1029/2001JD900229.

Huth R, Beck C, Philipp A, Demuzere M, Ustrnul Z, Cahynová M, Kyselý J, Tveito OE. 2008. Classifications of Atmospheric Circulation Patterns. Annals of the New York Academy of Sciences 1146(1): 105-152. DOI: 10.1196/annals.1446.019.

Küttel M, Luterbacher J, Wanner H. 2010. Multidecadal changes in winter circulation-climate relationship in Europe: frequency variations, within-type modifications, and long-term trends. Climate Dynamics 36(5-6): 957-972. DOI: 10.1007/s00382-009-0737-y.

Lorenzo MN, Ramos AM, Taboada JJ, Gimeno L. 2011. Changes in Present and Future Circulation Types Frequency in Northwest Iberian Peninsula. PLOS ONE 6(1). DOI: 10.1371/journal.pone.0016201.

Lucas-Picher P, Cattiaux J, Bougie A, Laprise R. 2016. How does large-scale nudging in a regional climate model contribute to improving the simulation of weather regimes and seasonal extremes over North America? Climate Dynamics 46(3-4): 929-948. DOI: 10.1007/s00382-015-2623-0. 
608

609

610

611

612

613

614

615

616

617

618

619

620

621

622

623

624

625

626

627

628

629

630

631

632

633

634

635

636

637

638

639

640

641

642

643

644

645

646

647

McKendry IG, Stahl K, Moore RD. 2006. Synoptic sea-level pressure patterns generated by a general circulation model: comparison with types derived from NCEP/NCAR re-analysis and implications for downscaling. International Journal of Climatology 26(12): 1727-1736. DOI: 10.1002/joc.1337.

Michelangeli P-A, Vautard R, Legras B. 1995. Weather Regimes: Recurrence and Quasi Stationarity. Journal of Atmospheric Sciences 52: 1237-1256. DOI: 10.1175/15200469(1995)052<1237:WRRAQS>2.0.CO;2.

Moss RH, Edmonds JA, Hibbard KA, Manning MR, Rose SK, Vuuren DP van, Carter TR, Emori S, Kainuma M, Kram T, MeehI GA, Mitchell JFB, Nakicenovic N, Riahi K, Smith SJ, Stouffer RJ, Thomson AM, Weyant JP, Wilbanks TJ. 2010. The next generation of scenarios for climate change research and assessment. Nature 463(7282): 747-756. DOI: 10.1038/nature08823.

Murawski A, Bürger G, Vorogushyn S, Merz B. 2016. Can local climate variability be explained by weather patterns? A multi-station evaluation for the Rhine basin. Hydrology and Earth System Sciences 20(10): 4283-4306. DOI: 10.5194/hess-20-4283-2016.

Nied M, Pardowitz T, Nissen K, Ulbrich U, Hundecha Y, Merz B. 2014. On the relationship between hydro-meteorological patterns and flood types. Journal of Hydrology 519: 3249-3262. DOI: 10.1016/j.jhydrol.2014.09.089.

Nuissier O, Joly B, Joly A, Ducrocq V, Arbogast P. 2011. A statistical downscaling to identify the largescale circulation patterns associated with heavy precipitation events over southern France. Quarterly Journal of the Royal Meteorological Society 137(660): 1812-1827. DOI: 10.1002/qj.866.

Obled C, Bontron G, Garçon R. 2002. Quantitative precipitation forecasts: a statistical adaptation of model outputs through an analogues sorting approach. Atmospheric Research 63(3-4): 303-324. DOI: 10.1016/S0169-8095(02)00038-8.

Pastor MA, Casado MJ. 2012. Use of circulation types classifications to evaluate AR4 climate models over the Euro-Atlantic region. Climate Dynamics 39(7-8): 2059-2077. DOI: 10.1007/s00382-012-14492.

Philipp A, Della-Marta PM, Jacobeit J, Fereday DR, Jones PD, Moberg A, Wanner H. 2007. Long-Term Variability of Daily North Atlantic-European Pressure Patterns since 1850 Classified by Simulated Annealing Clustering. Journal of Climate 20(16): 4065-4095. DOI: 10.1175/JCLI4175.1.

Planchon O, Quénol H, Dupont N, Corgne S. 2009. Application of the Hess-Brezowsky classification to the identification of weather patterns causing heavy winter rainfall in Brittany (France). Natural Hazards and Earth System Sciences 9(4): 1161-1173. DOI: 10.5194/nhess-9-1161-2009.

Plaut G, Simonnet E. 2001. Large-scale circulation classification, weather regimes, and local climate over France, the Alps and Western Europe. Climate Research 17(3): 303-324. DOI: 10.3354/cr017303.

R Core Team. 2016. R A Language and Environment for Statistical Computing. R Foundation for Statistical Computing: Vienna, Austria.

Renard B, Lall U. 2014. Regional frequency analysis conditioned on large-scale atmospheric or oceanic fields. Water Resources Research 50(12): 9536-9554. DOI: 10.1002/2014WR016277.

Sanchez-Gomez E, Somot S, Déqué M. 2009. Ability of an ensemble of regional climate models to reproduce weather regimes over Europe-Atlantic during the period 1961-2000. Climate Dynamics 33(5): 723-736. DOI: 10.1007/s00382-008-0502-7. 
648

649

650

651

652

653

654

655

656

657

658

659

660

661

662

663

664

665

666

667

668

669

670

671

672

673

674

675

676

677

678

679

680

Santos JA, Belo-Pereira M, Fraga H, Pinto JG. 2016. Understanding climate change projections for precipitation over Western Europe with a weather typing approach. Journal of Geophysical Research 121(3): 2015JD024399. DOI: 10.1002/2015JD024399.

Sénési S, Bougeault $P$, Chèze J-L, Cosentino $P$, Thepenier R-M. 1996. The Vaison-La-Romaine Flash Flood: Mesoscale Analysis and Predictability Issues. Weather and Forecasting 11(4): 417-442. DOI: 10.1175/1520-0434(1996)011<0417:TVLRFF>2.0.CO;2.

Sheridan SC, Lee CC. 2010. Synoptic climatology and the general circulation model. Progress in Physical Geography 34(1): 101-109. DOI: 10.1177/0309133309357012.

Stephenson DB, Hannachi A, O'Neill A. 2004. On the existence of multiple climate regimes. Quarterly Journal of the Royal Meteorological Society 130(597): 583-605. DOI: 10.1256/qj.02.146.

Taylor KE, Stouffer RJ, Meehl GA. 2012. An overview of CMIP5 and the experiment design. Bulletin of the American Meteorological Society 93(4): 485-498. DOI: 10.1175/BAMS-D-11-00094.1.

Teweles J, Wobus H. 1954. Verification of prognosis charts. Bulletin of the American Meteorological Society 35(10): 455-463.

Tramblay Y, Neppel L, Carreau J. 2011. Brief communication - Climatic covariates for the frequency analysis of heavy rainfall in the Mediterranean region. Natural Hazards and Earth System Sciences 11(9): 2463-2468. DOI: 10.5194/nhess-11-2463-2011.

Tramblay Y, Neppel L, Carreau J, Najib K. 2013. Non-stationary frequency analysis of heavy rainfall events in southern France. Hydrological Sciences Journal 58(2): 280-294. DOI: 10.1080/02626667.2012.754988.

Trenberth KE, Fasullo JT, Shepherd TG. 2015. Attribution of climate extreme events. Nature Climate Change 5(8): 725-730. DOI: 10.1038/nclimate2657.

Ullmann A, Fontaine B, Roucou P. 2014. Euro-Atlantic weather regimes and Mediterranean rainfall patterns: present-day variability and expected changes under CMIP5 projections. International Journal of Climatology 34(8): 2634-2650. DOI: 10.1002/joc.3864.

Vrac M, Hayhoe K, Stein M. 2007. Identification and intermodel comparison of seasonal circulation patterns over North America. International Journal of Climatology 27(5): 603-620. DOI: 10.1002/joc.1422.

Wetterhall F, Halldin S, Xu C. 2005. Statistical precipitation downscaling in central Sweden with the analogue method. Journal of Hydrology 306(1-4): 174-190. DOI: 10.1016/j.jhydrol.2004.09.008.

Wilby RL, Quinn NW. 2013. Reconstructing multi-decadal variations in fluvial flood risk using atmospheric circulation patterns. Journal of Hydrology 487: 109-121. DOI: 10.1016/j.jhydrol.2013.02.038. 